NASA Technical Memorandum 106975

AIAA-95-3109

\title{
Jet Mixing in a Reacting Cylindrical Crossflow
}

M.Y. Leong and G.S. Samuelsen

UCI Combustion Laboratory

University of California

Irvine, California

J.D. Holdeman

Lewis Research Center

Cleveland, Ohio

Prepared for the

31st Joint Propulsion Conference and Exhibit cosponsored by AIAA, ASME, SAE, and ASEE

San Diego, California, July 10-12, 1995

National Aeronautics and

Space Administration 


\title{
JET MIXING IN A REACTING CYLINDRICAL CROSSFLOW
}

\author{
M.Y. Leong* and G.S. Samueisen ${ }^{+}$ \\ UCI Combustion Laboratory \\ University of California \\ Irvine, California 92717-3550 \\ J.D. Holdeman ${ }^{\ddagger}$ \\ National Aeronautics and Space Administration \\ Lewis Research Center \\ Cleveland, Ohio 44135
}

\begin{abstract}
$\underline{\text { Abstract }}$
This paper addresses the mixing of air jets into the hot, fuel-rich products of a gas turbine primary zone. The mixing, as a result, occurs in a reacting environment with chemical conversion and substantial heat release. The geometry is a crossflow confined in a cylindrical duct with side-wall injection of jets issuing from round orifices. A specially designed reactor, operating on propane, presents a uniform mixture without swirl to mixing modules consisting of $8,9,10$, and 12 holes at a momentum-flux ratio of 57 and a jet-to-mainstream mass-flow ratio of 2.5. Concentrations of $\mathrm{O}_{2}, \mathrm{CO}_{2}, \mathrm{CO}$, and $\mathrm{HC}$ are obtained upstream, downstream, and within the orifice plane. $\mathrm{O}_{2}$ profiles indicate jet penetration while $\mathrm{CO}_{2}, \mathrm{CO}$, and $\mathrm{HC}$ profiles depict the extent of reaction. Jet penetration is observed to be a function of the number of orifices and is found to affect the mixing in the reacting system. The results demonstrate that one module (the 12hole) produces near-optimal penetration defined here as jet penetration closest to the module halfradius, and hence the best uniform mixture at a plane one duct radius from the orifice leading edge.
\end{abstract}

* Graduate Researcher

Professor, Corresponding Author,

Associate Fellow, AIAA

- Senior Research Engineer.

Associate Fellow. AIAA

Copyright $\odot 1995$ by the American Institute of Aeronautics and Astronautics. Inc. No copyright is asserted in the United States under Title 17. U.S. Code. The U.S. Government has a royalty-free license to exercise all rights under the copyright claimed herein for Governmental purposes. All other rights are reserved by the copyright owner.
Nomenclature

DR jet-to-mainstream density ratio

h orifice axiat height, or round hole diameter

J jet-to-mainstream momentum-flux ratio $=\left(\rho V^{2}\right)_{j e t} /\left(\rho V^{2}\right)_{\text {main }}$

MR jet-to-mainstream mass-flow ratio

$P \quad$ operating pressure

$\mathrm{R}$ inner radius of the quick mix module

$T_{\text {main }}$ mainstream temperature

$\mathrm{T}_{\text {jet }}$ jet air temperature

$\mathrm{V}_{\text {ref }}$ reference velocity

$\mathrm{z}$ axial distance from leading edge of orifice

$\phi$ equivalence ratio $=(\text { fuel/air })_{\text {local }} /(\text { fuel/air })_{\text {stochchiomeric }}$

\section{$\underline{\text { Introduction }}$}

Jets in a crossflow play an integral role in practical combustion systems such as can and annular gas turbine combustors in conventional systems, and the Rich-Burn/Quick-Mix/LeanBurn (RQL) combustor utilized in stationary applications and proposed for advanced subsonic and supersonic transports. The success of the RQL combustor rests with the performance of the quick-mixing section that bridges the rich and lean zones. The mixing of jet air with a rich crossflow to bring the reaction to completion in the lean zone must be performed rapidly and thoroughly in order to decrease the extent of near-stoichiometric fluid pocket formation. Fluid pockets at near-stoichiometric equivalence ratios are undesirable because the high temperatures attained accelerate pollutant formation kinetics. The present study is a model experiment to reveal the mixing processes that occur when jet air is introduced into the hot effluent emanating from a fuel-rich reaction zone. 


\section{Background}

Jet mixing into a crossflow has been studied extensively because of its wide range of applicability to such diverse fields as gas turbine cooling and staging, fuel-air premixing, VSTOL aircraft, and pollutant discharge from stacks or pipes. In a confined crossflow problem such as that encountered in the quick-mixing region of the RQL combustor, flow properties such as the jet-to-mainstream density and momentum-flux ratios as well as the geometries constraining the jet and crossflow influence the degree of mixing that occurs. In a confined subsonic crossflow system the most important flow variable is the jet-to-mainstream momentum-flux ratio, J (Holdeman, 1993). The momentum-flux ratio must be determined before a configuration (e.g., orifice number, shape, and placement) can be designed.

Extensive experimental and numerical studies on jets in a confined crossflow have been performed under non-reacting conditions to examine the effect of jet orifice configurations on mixing in different duct geometries at various momentum-flux ratios. Non-reacting studies of jets issuing into rectangular (Bain, Smith, and Holdeman, 1992, 1993, 1994; Liscinsky, et al., 1992; Liscinsky, True, and Holdeman, 1993, 1994, 1995) and cylindrical duct geometries (Hatch, et al., 1995a, 1995b; Kroll, et al., 1993; Oechsle, Mongia, and Holdeman, 1992 and 1993; Smith, Talpallikar, and Holdeman, 1991; Sowa, et al., 1994; Talpallikar, et al., 1992; Vranos, et al., 1991) have been studied for their applicability to annular and can combustor configurations.

Among the primary goals of non-reacting research on jet mixing in a confined crossflow is the ability to determine orifice configurations that lead to optimal mixing within a specified duct length. In the cylindrical duct geometry, experimental surveys of the effect of momentum-flux ratio and the shape, orientation, and number of orifices on mixing were performed by Hatch, et al. (1995a) and Kroll, et al. (1993) in order to gain a mechanistic understanding of jet penetration and mixing dynamics. A systematic optimization scheme on experimental data was then undertaken by Sowa, et al. (1994) to determine the orifice configurations leading to optimal mixing at a set momentum-flux ratio. A non-linear relationship between orifice shape, number, and orientation was revealed with respect to mixing, which allowed for the possibility of more than one optimal orifice combination.

Non-reacting flow experiments have been conducted in lieu of reacting experiments in order to benefit from the advantages (less complicated, more amenable to diagnostic interrogation) of the non-reacting environment. As a result, although various numerical studies (Hatch, et al., 1995b; Oechsle, Mongia, and Holdeman, 1994; Oechsle and Holdeman, 1995; Talpallikar, et al., 1992) have been undertaken to characterize the flowfield of jets entering a reacting cylindrical RQL geometry, only one experimental study is reported in the open literature. Zarzalis, et al. (1992) performed a reacting experiment to determine the effect of different inlet pressures and temperatures on $\mathrm{NO}_{\mathrm{x}}$ emissions. However, their study did not address the mechanistic processes governing jet mixing.

The purpose of the present study was to obtain, for a rich reacting flow in a cylindrical RQL simulation, species concentration distributions in order to evaluate jet penetration and mixing, and provide an initial database for numerical simulations.

\section{Experiment}

\section{Facility}

An atmospheric model RQL combustion facility depicted in Figure 1 was designed explicitly for this experiment. The challenge was to produce a consistent and uniform effluent of non-swirling, rich products into cylindrical jet mixing modules. The experiment consisted of a refractory-lined stainless steel can which supported the rich combustion zone and which subsequently transitioned to a plenum-fed quickmixing section that exhausted into a fume hood. A digital encoder monitored the traversing of the experimental apparatus while the emissions probe remained fixed to the optical table.

Propane was used since it simulates the chemistry associated with the higher hydrocarbon structure of jet fuel without complicating the experiment with liquid tuel atomization. Rich combustion products were generated by burning a swirl-stabilized premixed propane and air mixture initially at room 


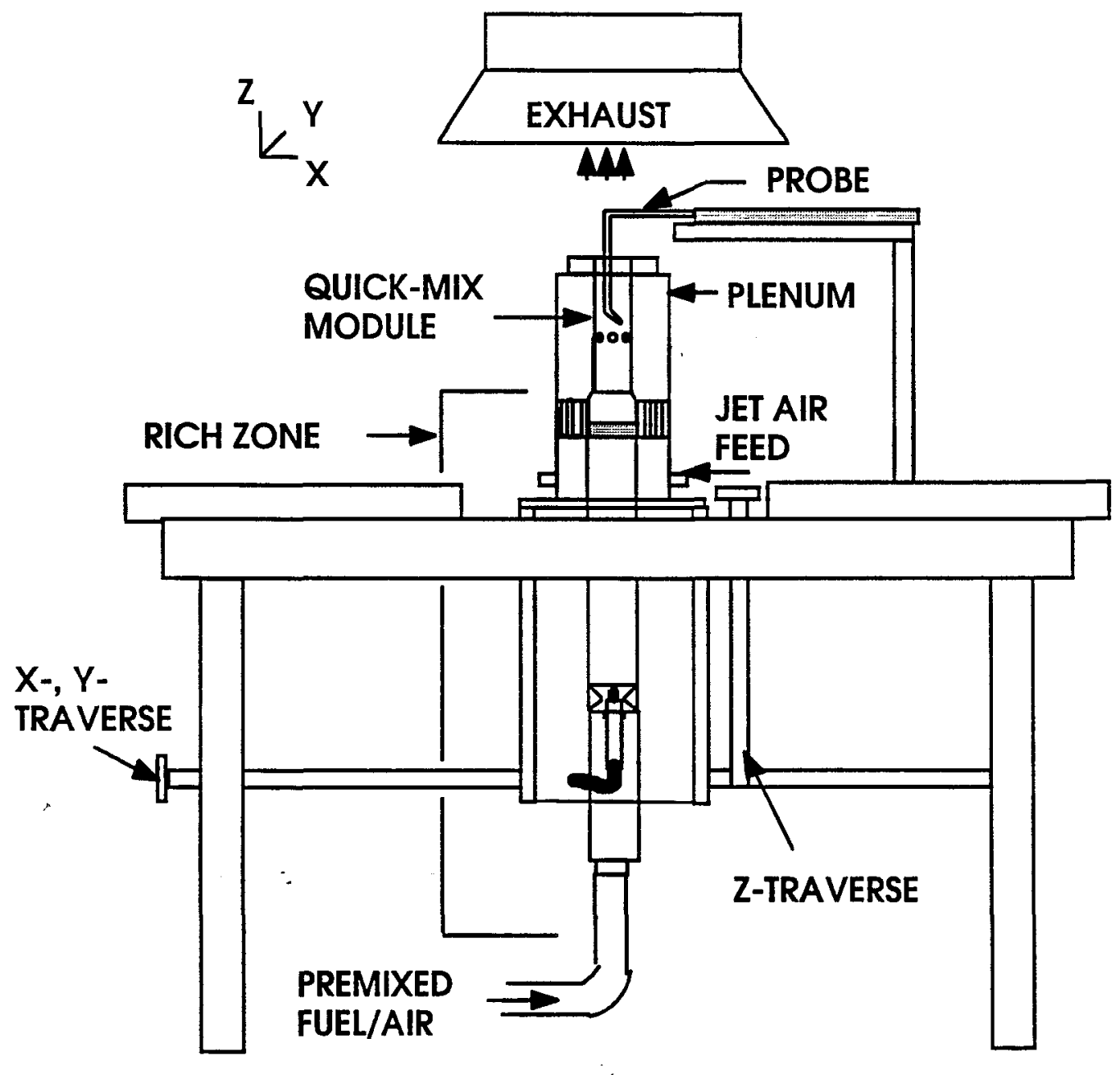

Figure 1. Reacting Flow Test Stand Schematic

temperature $-(293 \mathrm{~K})$. A porous ceramic matrix was installed to dissipate the swirl in the flow and ensure a non-swirling, uniform rich product entering the quick-mix section.

The plenum surrounding the combustor and quick-mixing section was fed by four individually metered air ports near the bottom of the chamber. A high-temperature steel flow straightener placed between the combustor and plenum walls was used to condition and promote an equal distribution of jet air entering the quickmixing module. A pressure tap and thermocouple monitored the pressure drop across the quick-mixing module and the temperature of the jet air.

The modular quick-mixing section allowed for the testing of different jet orifice configurations by interchanging the $80 \mathrm{~mm}$ inner diameter, $85 \mathrm{~mm}$ outer diameter cylindrical quartz modules (Figure 2a). The modules were $280 \mathrm{~mm}$ long with the orifices spaced equally along the circumference of the tubing. The four geometries tested were the $8,9,10$, and 12 round hole configurations.

\section{Data Acquisition}

A double-jacketed water-cooled stainless steel probe $8 \mathrm{~mm}$ outside diameter was used to extract gas samples from the quick-mixing section. The probe was fabricated with a 45degree bend one inch from the tip. The probe design was influenced by the research of Sowa, et al. (1994), who found that a thermocouple probe with a 45-degree angled tip was the best design in acquiring temperature in these types of flows. The plane of the probe tip was positioned 
such that its tip pointed toward the center of the sector wail.

Species concentrations of $\mathrm{CO}_{2}, \mathrm{CO}, \mathrm{O}_{2}$, and unburned $\mathrm{HC}$ were obtained by drawing gas samples from selected points in the flowfield planes. The samples were drawn from the probe and directed through a heated line connected to the emission analyzers. The analyzers utilized non-dispersed infrared (NDIR), paramagnetic, and flame ionization detection (FID) to measure $\mathrm{CO}_{2}$ and $\mathrm{CO}, \mathrm{O}_{2}$, and unburned $\mathrm{HC}$ species, respectively. The highest full-scale reading of the $\mathrm{CO}$ analyzer is $3 \%$, and readings above $3 \%$ may be inaccurate due to the non-linearity of the fourth-order polynomial calibration curve. However, the general trends of the $\mathrm{CO}$ readings provide a measure of the extent of reaction in the flow.

Six planes of data were obtained per module as depicted in Figure $2 \mathrm{~b}$. With $\mathrm{z}$ referring to the axial distance, $\mathbf{R}$ defined as the module inner radius, and $\mathrm{h}$ defined as the orifice axial height, the planes were situated, with the origin $z=0$ set at the leading edge of the orifice, at positions

(1) one module radius upstream ( $\mathrm{z} / \mathrm{R}=-1$ ),

(2) at the orifice leading edge $(z / R=0)$,

(3) one-half the orifice axial height $(\mathrm{z} / \mathrm{R}=(\mathrm{h} / 2) / \mathrm{R})$,

(4) at the orifice axial height ( $z / R=h / R)$,

(5) one module radius downstream $(z / R=1)$,

(6) two module radii downstream $(z / R=2)$.

Assuming flow symmetry, a sector of data was obtained to represent the entire plane. Each plane of data consisted of 16 data points distributed across a sector that encompassed two orifices (Figure 3 ). The data grid density increased as the number of orifices increased since the size of the sectors decreased. A $90^{\circ}$ sector was used for the 8 -hole module, an $80^{\circ}$ sector for the 9 -hole module, a $72^{\circ}$ sector for the 10 -hole module, and a $60^{\circ}$ sector for the 12 hole module.

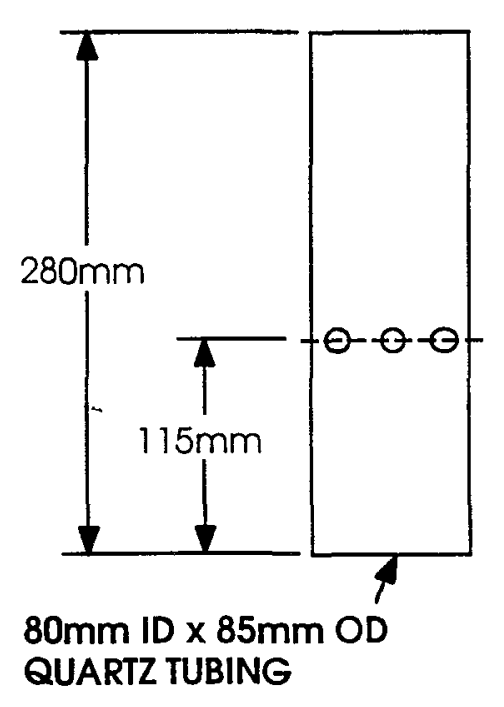

(a)

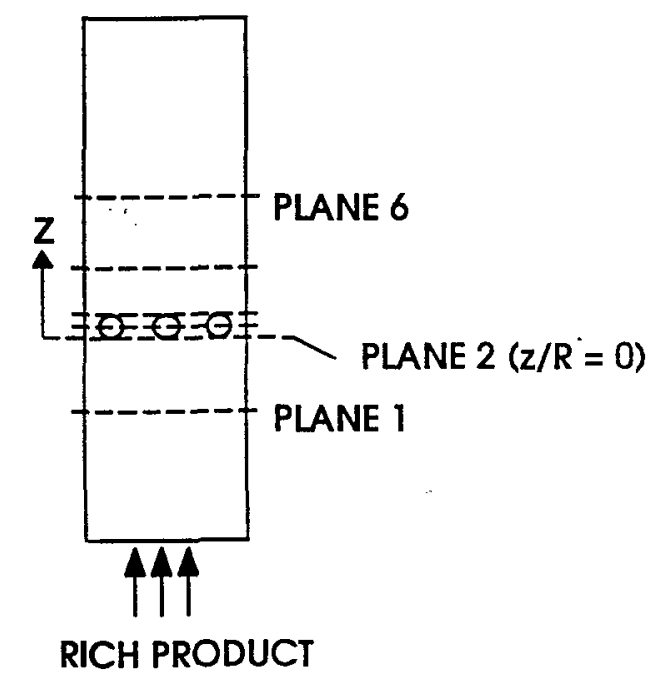

(b)

Figure 2. (a) Quartz Module Dimensions, and (b) Measurement Planes 


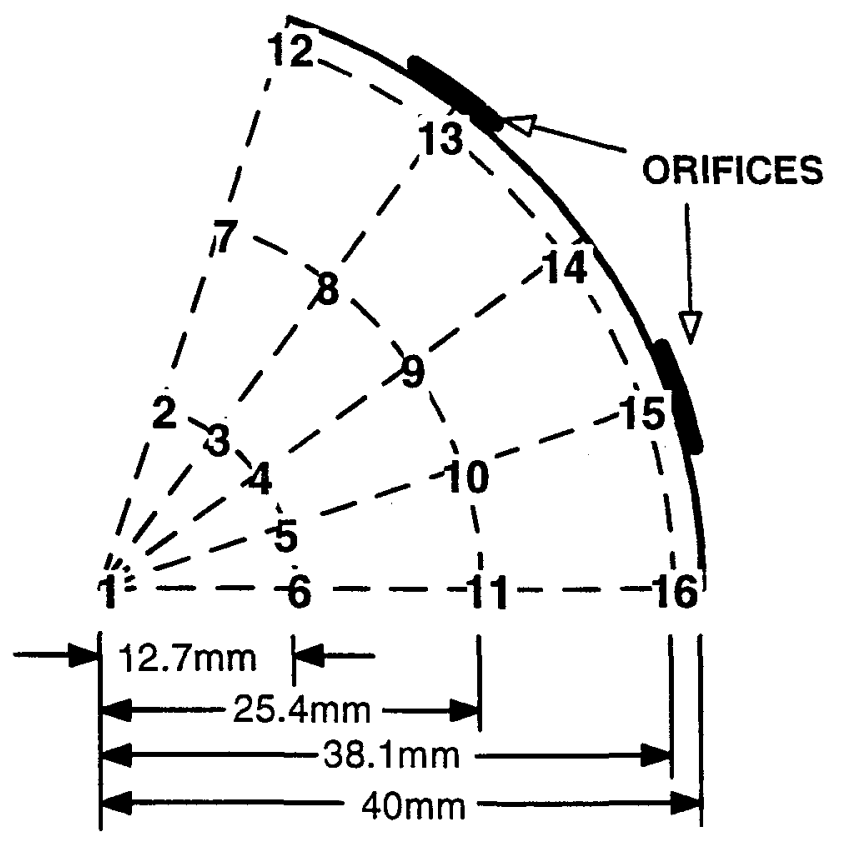

Figure 3. Representative 16-Point Grid Over Two Orifices

\section{Experimental Conditions}

The operating conditions under which the tests were run are noted in Table 1. The experiment was designed to operate at a momentum-flux ratio $J$ of 60 . The measured momentum-flux ratio was 57 . The total geometrical orifice area of $1244 \mathrm{~mm}^{2}$ for each quick-mix module was based on a discharge coefficient of 0.73 .

Table 1. Operating Conditions

\begin{tabular}{lc}
\hline Parameter & Value \\
\hline operating P $(\mathrm{kPa})$ & 1.01 \\
rich equivalence ratio $\phi$ & 1.66 \\
overall $\phi$ & 0.45 \\
$\mathrm{~T}_{\text {main }}(\mathrm{K})$ & 1500 \\
$\mathrm{~T}_{\text {ied }}(\mathrm{K})$ & 480 \\
$\mathrm{~V}_{\text {ref }}(\mathrm{m} / \mathrm{s})$ & 18 \\
momentum-flux ratio J & 57 \\
mass-flow ratio MR & 2.5 \\
density ratio DR & 3.3
\end{tabular}

\section{Results and Discussion}

The results are presented in three different formats: (1) histograms to depict the distribution of data, (2) contour plots of radial-axial sections to show the axial evolution of the flow, and
(3) contour plots of sectors to show planar symmetry and the extent of mixing and reacting processes.

The description of the reacting flow field of the 8-hole case is discussed first to gain a sense of jet mixing and reaction in a rich reacting crossflow.

\section{Species Distribution: 8-Hole Case}

Figures $4 \mathrm{a}$ and $4 \mathrm{~b}$ show the histogram distributions of $\mathrm{O}_{2}, \quad \mathrm{CO}_{2}, \mathrm{CO}$, and $\mathrm{HC}$ concentrations measured for the 8 -hole configuration. The histograms provide information on the species distribution per plane at 16 grid points. Point 1 lies in the center of the module, Points 2-6 lie along the arc length at one-third of the module radius, Points 7-11 lie at two-thirds of the module radius, and Points 1216 lie near the module radius $R$. Points $3,5,8$, 10,13 , and 15 are aligned with the orifices.

The distributions at Plane 1 reveal uniform rich zone concentrations of $0 \% \mathrm{O}_{2}, 5.2 \% \mathrm{CO}_{2}$, and $8.8 \% \mathrm{CO}$. The $\mathrm{HC}$ concentrations. while overall relatively uniform, show more variability. $1 \%$ to $1.6 \%$ concentrations occur in the central core while higher concentrations up to $2 \%$ are present in the wall region. The higher HC concentrations observed near the wall likely result from the lower temperatures in the wall 


\section{$\mathrm{O}_{2}(\%) \quad \mathrm{CO}_{2}(\%)$}

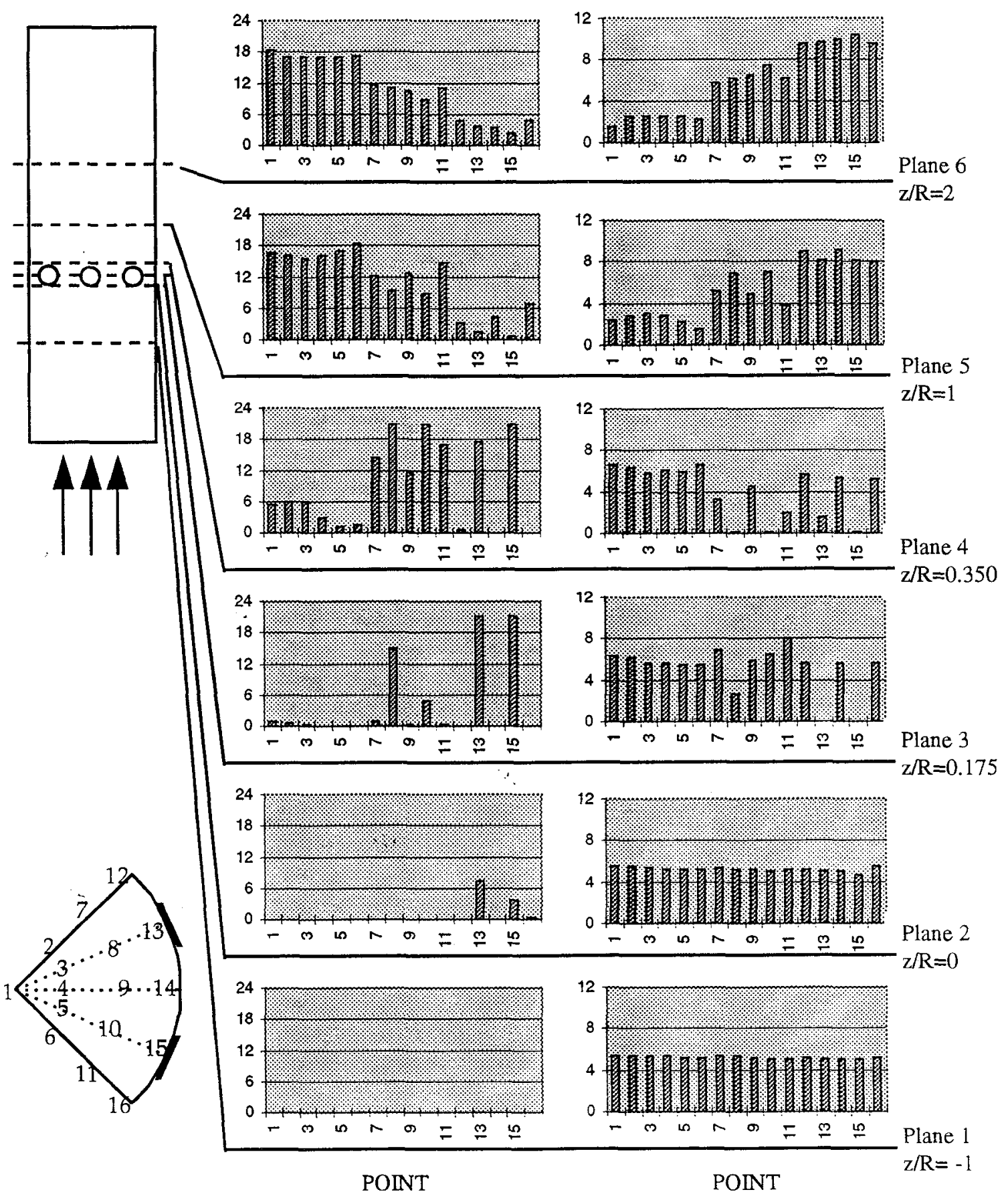

Figure 4a. $\mathrm{O}_{2}, \mathrm{CO}_{2}$ Concentration Distribution for the 8 Hole Module 


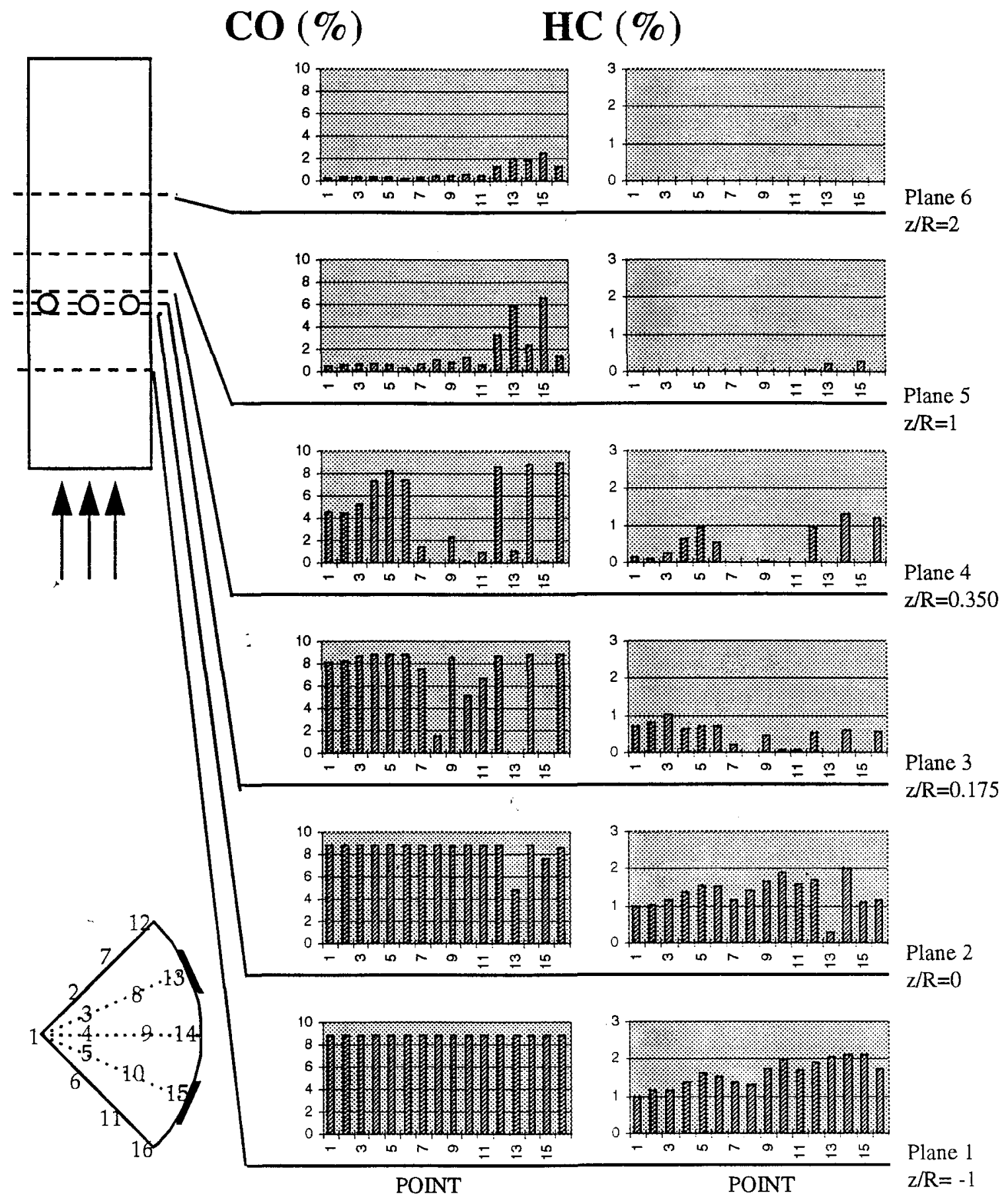

Figure 4b. CO, HC Concentration Distribution for the 8 Hole Module 
region as a consequence of the convective cooling of the outer wall by the plenum air.

From analyzing the distribution of species over an axial history, inferences can be established in relation to jet penetration and mixing. The $\mathrm{O}_{2}$ charts in Figure $4 \mathrm{a}$, for example, show the evolution of jet penetration from the leading edge of the orifices (Plane 2). Farther downstream at the orifice mid-height plane (Plane 3), the jets fill the outer mixer radius to near-21\% concentrations at Points 13 and 15 , which are aligned with the orifices. The jet fluid then migrates toward the second radial band (Plane 4), as seen by $21 \% \mathrm{O}_{2}$ concentrations at Points 8 and 10 , and begins to disperse, as noted by the appearance of oxygen at neighboring Points 7, 9, and 11. At one and two mixer radii downstream of the orifice leading edge, the jet fluid penetrates to the central core.

At the orifice leading edge and mid-orifice planes (Planes 2 and 3 ), the points at which $\mathrm{O}_{2}$ levels are measured (Points 13 and 15 in Plane 2, Points 8, 10, 13, and 15 in Plane 3) correspond to the decrease or increase in the other species concentrations measured at the same points. The decrease in $\mathrm{CO}_{2}$ levels at Points 13 and 15 , and at Points 8 and 10 at Plane 3 is attributed to jet dilution (see Figure $4 a$ ). The slight increase of $\mathrm{CO}_{2}$ concentrations at other points in the plane reflect reaction.

Similarly, the dilution of $\mathrm{CO}$ and $\mathrm{HC}$ (Figure 4 b) at Points 13 and 15 correlates to the presence of $\mathrm{O}_{2}$ concentrations at the same points in Plane 2. The reaction of $\mathrm{CO}$ and $\mathrm{HC}$ is corroborated by a comparison between the overall concentrations measured at Planes 2, 3, and 4. Plane 3 shows a decimation of $\mathrm{HC}$ concentrations that had been abundant in Plane 2. The $\mathrm{CO}$ concentrations are also decreased, though not as rapidly as $\mathrm{HC}$, because of the slower $\mathrm{CO}$ reaction. Between Planes 3 and 4 , additional $\mathrm{CO}$ has reacted while no further reaction of $\mathrm{HC}$ occurs.

The bulk of the reaction takes place in the zone downstream of the holes (between Planes 4-5) where the jets penetrate toward the center and begin to disperse throughout the crossflow. In this region of reaction between Planes 4 and Plane 5, $\mathrm{CO}$, concentrations rise while $\mathrm{CO}$ and $\mathrm{HC}$ concentrations decrease significantly. Most of the reaction terminates by the $z / R=1$ plane (Plane 5) since the magnitude of the profiles measured at that plane and at $\mathrm{z} / \mathrm{R}=2$ (Plane 6) do not change substantially.
The contour plots in Figures $5 \mathrm{a}$ and $5 \mathrm{~b}$ give an alternative presentation of the species concentration profiles. The radial-axial profiles (Figure 5a) illustrate the longitudinal evolution of jet penetration and flowfield characteristics in the module while the sector plots (Figure 5b) offer another view which indicates planar species distribution symmetry.

The radial-axial plots (e.g., in Figure 5a) depict two cross-sections: one which is aligned with the wall midpoint (a "midplane" crosssection) and one which is aligned with the orifice (a "centerplane" cross-section). The midplane cross-section is an average of the three lines of data aligned with the wall while the centerplane cross-section is an average of the two lines of data aligned with the hole. The data are plotted on axial versus radial length scales $z$ and $r$ normalized with respect to the mixer radius $R$. The sector plots such as those seen in Figure 5b are an unaveraged depiction of the planar interpolation of the 16 points of data obtained per sector.

From Figures $5 \mathrm{a}$ and 5b, the species entering the module are generally uniform up to the plane of jet entry. Evidence of early jet penetration is apparent at the orifice leading edge $(\mathrm{z} / \mathrm{R}=0)$. Full jet penetration is apparent for all species by the orifice trailing edge $(\mathrm{z} / \mathrm{R}=0.350)$.

Jet penetration as seen in the $\mathrm{O}_{2}$ protiles is represented by a high concentration of jet tuid in the orifice region that enters the crosstlow nearly intact before dispersing throughout the mixer radius (see Figure $5 \mathrm{a}$ ). The jets appear to penetrate toward the center within one mixer radius length (i.e. at Plane $5, \mathrm{z} / \mathrm{R}=1$ ).

The $\mathrm{O}_{2}, \mathrm{CO}_{2}$, and $\mathrm{CO}$ centerplane profiles show a transition region in the jet wake formed by the initial reaction between the jets and the entrained rich crossflow. Downstream of the $\mathrm{z} / \mathrm{R}=1$ plane, the penetrating jets displace the rich reacting fluid toward the wall, as evidenced by the pocket of high $\mathrm{CO}$ concentration at the wall. The small pocket of $\mathrm{CO}$ subsequently disappears as $\mathrm{CO}$ reacts with the jet to form $\mathrm{CO}_{2}$. This source of $\mathrm{CO}_{2}$ increases concentrations at the wall from the $z / R=1$ to $z / R=2$ plane.

In addition to showing the extent of reaction and mixing occurring between the jets and the rich mainstream, the sector plots in Figure $5 \mathrm{~b}$ give an indication of jet and flow field symmetry. Although at the orifice midplane $(\mathrm{z} / \mathrm{R}=0.175)$ the first jet appears to dominate over the second jet, by the orifice trailing edge 
( $\mathrm{z} / \mathrm{R}=0.350$ ) the jet flows are essentially symmetrical. At the $z / R=1$ plane, the flow field of stratified concentration bands is radically different from the previous plane showing discrete jets. At the $z / R=2$ plane the stratified bands become more well formed but the overall flow field does not change drastically. This observation as well as the virtual disappearance of $\mathrm{CO}$ and $\mathrm{HC}$ between the $\mathrm{z} / \mathrm{R}=1$ and $\mathrm{z} / \mathrm{R}=2$ planes show that the jets have almost entirely reacted with the rich crossflow within one duct radius of entry.

Species Concentration: 8, 9, 10, and 12 Hole Modules

The mixing and reaction performance of the four orifice configurations is assessed with a comparison of radial-axial and sector contour plots for each module. The objective of comparing the four mixing modules is to determine a configuration that leads to optimal jet penetration and hence optimal mixing and reaction within one duct radius of the jet entrance (i.e., at $\mathrm{z} / \mathrm{R}=1$ ).

Figures $6,8,10$, and 12 depict radial-axial cross-sections (for $\mathrm{O}_{2}, \mathrm{CO}_{2}, \mathrm{CO}$, and $\mathrm{HC}$, respectively) while the corresponding planar sector plots are presented in Figures 7, 9, 11, and 13.

\section{Jet Penetration and Dispersion}

The effect of the number of holes on jet penetration is better illustrated in the radial-axial $\mathrm{O}_{3}$ distributions of Figure 6. As the number of holes is increased, the jet trajectory moves away from the centerline toward the wall, and the bulk of jet fluid occurring at the centerline between the $z / R=1$ and $z / R=2$ planes decreases.

High jet penetration resulting in jet impingement at the centerline occurs in the 8hole case and results in a large agglomeration of $\mathrm{O}_{2}$ in the central core. This condition suggests that the 8-hole module is an overpenetrating case which is undesirable since the oxygen tends to accumulate in the center rather than disperse, mix, and react with the crossflow. Overpenetration also leads to less reaction since the accumulation of jet fluid in the center decreases the area of the jet-crosstlow interface, or the promotion of reactant interaction. The 9and 10-hole cases also exhibit some degree of overpenetration as the outer fringe of jet fluid appears to intersect with the centerline by the $\mathrm{z} / \mathrm{R}=1$ plane.

The 12-hole case shows a jet trajectory that does not penetrate to the center at the $z / R=1$ plane. Without jet impingement, a more lateral spreading of jet mass, as evidenced by the smaller distribution range of oxygen concentration values across the mixer radius, is achieved. The midplane $\mathrm{O}_{2}$ profiles show that the 12-hole module exhibits a smaller band of fluid devoid of oxygen at the wall (indicated in orange and red) between the $\mathrm{z} / \mathrm{R}=1$ and $\mathrm{z} / \mathrm{R}=2$ planes. More rich mainstream flow reacts with rather than bypasses the jets in the 12-hole case to yield a more uniform distribution of $\mathrm{O}_{2}$ by the $\mathrm{z} / \mathrm{R}=1$ and $\mathrm{z} / \mathrm{R}=2$ planes.

For cylindrical crossflow geometries, several investigations have determined a jet penetration depth that leads to better mixing. In a numerical study performed by Talpallikar, et al. (1992), results suggest that optimal mixing occurs when the jet penetrates to the mid-radius. Kroll, et al. (1993) infers from experimental results that optimal mixing occurs when the jet penetrates to the radius that divides the mixer into an equal core and annular area, or at a radial distance $70 \%$ from the centerline. For the cases tested in this experiment, the mean jet trajectory intersects the $\mathrm{z} / \mathrm{R}=1$ plane at $1 / 4$ mixer radius away from the centerline for the 8 -hole case, $1 / 3$ mixer radius for the 9 -hole case, $3 / 8$ mixer radius for the 10 hole case, and $1 / 2$ mixer radius for the 12 -hole case. The Talpallikar, et al. and Kroll, et al. criteria support the observation that the 12-hole case offers the jet penetration that promotes the best mixing out of the configurations tested.

The corresponding cross-sectional contour plot for $\mathrm{O}_{2}$ (Figure 7) shows the jets entering the crossflow symmetrically. The stratified concentration distributions at $\mathrm{z} / \mathrm{R}=1$ (Plane 5) differ substantially from Plane 4 and not as drastically as Plane $6(\mathrm{z} / \mathrm{R}=2)$. Jet mixing and reaction occur within one duct radius of the entrance of the jets for all four modules.

It is observed again from the $\mathrm{O}_{2}$ sector plots that increasing the number of holes lowers jet penetration. By the orifice trailing edge all of the jet fluid should have entered and been accounted for in Plane 4 . The sector crosssections show a larger bulk of jet fluid occurring per orifice in the 8-hole case and a successive decrease in bulk jet fluid per orifice as the number of orifices increases. This decrease in 
mass flow is attributed to the decrease in area per orifice, since the jet velocity per orifice is constant for all four configurations. Decreasing the jet mass-flow rate per orifice decreases the jet momentum, which consequently diminishes jet penetration into the crossflow.

\section{Extent of Reaction}

A comparison of the $\mathrm{CO}_{2}$ concentration profiles for all four hole configurations (Figures 8 and 9) yields similar observations gained from the $\mathrm{O}_{2}$ species profiles in regard to the distribution of species concentrations. From the axial profiles (Figure 8) the 12-hole case appears to produce a more evenly dispersed $\mathrm{CO}_{2}$ field in both the midplane and centerplane. A continuous trail of near-zero $(0 \%$ to $4 \%$ blueviolet bands) $\mathrm{CO}_{2}$ concentration from the orifice to the central core that is present in the 8- and 9hole cases is absent in the 10- and 12-hole cases. From the sector profiles (Figure 9) the 12-hole case also appears to produce the highest overall amount of $\mathrm{CO}_{2}$ distributed in the sector plane at the $z / R=1$ and $z / R=2$ planes, which suggests that more complete reaction processes have occurred.

A sense of the extent of reaction can be gleaned from the radial-axial $\mathrm{CO}$ protiles (Figure 10). Between $z / R=1$ and $z / R=2$, the presence of $\mathrm{CO}$ in the wake of the jet coupled with an increase of $\mathrm{CO}_{2}$ in the same region suggests that the reaction of $\mathrm{CO}$ is a major contributor to the increased $\mathrm{CO}_{2}$ at the wall (see Figure 8). As the number of orifices increases, the pocket of rich CO-laden gases in the jet wake decreases in size. The greater lateral jet dispersement observed in the $\mathrm{O}_{2}$ profiles for the 12 -hole case probably aids in spreading the reaction throughout the mixer radius.

Figure 11 shows the planar cross-sectional view of the $\mathrm{CO}$ distribution. For all of the modules a majority of $\mathrm{CO}$ has been consumed by the $\mathrm{z} / \mathrm{R}=1$ plane. $\mathrm{CO}$-rich pockets in the jet wake can also be seen in the same plane. By the $\mathrm{z} / \mathrm{R}=2$ plane, the rich pockets have disappeared. Only the 12-hole case shows a CO distribution that is less than $1 \%$ for the entire sector.

A comparison of $\mathrm{HC}$ protiles (Figures 12 and 13) for each module shows rapid consumpuon of $\mathrm{HC}$ in the rich effluent by the orifice trailing edge (Plane 4).

\section{Summarv and Conclusions}

An experiment has been designed and successfully demonstrated to provide a test bed for the study of jet mixing in a rich reacting environment. In this demonstration, it was possible to determine jet penetration as well as to observe mixing and reacting processes for four round orifice configurations.

For a momentum-flux ratio of $J=57$, it was found (under atmospheric conditions) that:

- The data grid density and planar measurement distribution provide sufficient information to form general inferences and comparisons of mixing and reacting properties between various multiple-orifice configurations.

- The species concentration profiles for the four configurations share the same general behavior relative to jet penetration dynamics, including a completion of the reaction within one duct radius of the orifice leading edge.

- As the number of round orifices is increased, jet penetration decreases. Of the four hole configurations tested, the 12-hole module exhibits jet penetration closest to the mixer half-radius and thus appears to produce the best uniform mixing by the $\mathrm{z} / \mathrm{R}=1$ plane.

- In the 8-, 9-, and 10-hole cases, the jet fluid gravitates to and accumulates in the central core of the mixer rather than dispersing laterally throughout the radius of the mixer. These overpenetrating cases allow the rich crossflow to pass through the quick-mixing region along the wall. The optimal penetration occurring in the 12-hole module maximizes the reactant interaction.

- The separation of reaction from mixing cannot, at this juncture, be determined. A conserved scalar measurement of, for example, an inert gas tracer is necessary to independently characterize the mixing in the flowfield.

Although the profiles obtained are sufficient to indicate general flow characteristics and allow a comparison between mixers. a denser data grid would be advantageous in order to capture specific gradients more precisely. 


\section{Acknowledgments}

This work was funded under a grant from the NASA-Lewis Research Center (Grant NAG3$1110)$.

Appreciation is especially extended to Dr. William A. Sowa for contributing to the initial stages of the reacting flow experiment.

\section{$\underline{\text { References }}$}

Bain, D.B., Smith, C.E., and Holdeman, J.D. (1994). CFD Assessment of Orifice Aspect Ratio and Mass-flow Ratio on Jet Mixing in Rectangular Ducts. AIAA-94-0218 (Also NASA TM 106434).

Bain, D.B., Smith, C.E., and Holdeman, J.D. (1993). CFD Mixing Analysis of Axially Opposed Rows of Jets Injected into Confined Crossflow. Accepted for publication in Journal of Propulsion and Power (See also AIAA-932044 and NASA TM 106179).

Bain, D.B, Smith, C.E., and Holdeman, J.D. (1992). CFD Mixing Analysis of Jets Injected from Straight and Slanted Slots into Confined Crossflow in Rectangular Ducts. AIAA-92-3087 (Also NASA TM 105699).

Hatch, M.S., Sowa, W.A., Samuelsen, G.S., and Holdeman, J.D. (1995a). Jet Mixing into a Heated Cross Flow in a Cylindrical Duct: Influence of Geometry and Flow Variations. Journal of Propulsion and Power, 11, 393-402. (See also -AIAA-92-0773 and NASA TM 105390).

Hatch, M.S., Sowa, W.A., Samueisen, G.S., and Holdeman, J.D. (1995b). Influence of Geometry and Flow Variations on NO Formation in the Quick Mixer of a Staged Combustor. Journal of Engineering for Gas Turbines and Power (in press).

Holdeman, J.D. (1993). Mixing of Multiple Jets with a Confined Subsonic Crossflow. Prog. Energy Combust. Sci, 7, 31-70. (Also AIAA-912458: NASA TM 104412).

Kroll, J.T., Sowa, W.A., Samuelsen, G.S., and Holdeman, J.D. (1993). Optimization of
Circular Orifice Jets Mixing into a Heated Cross Flow in a Cylindrical Duct. AIAA-93-0249 (Also NASA TM 105984).

Liscinsky, D.S., True, B., and Holdeman, J.D. (1995). Crossflow Mixing of Noncircular Jets. Accepted for publication in Journal of Propulsion and Power (See also AIAA-95-0732 and NASA TM 106865).

Liscinsky, D.S., True, B., and Holdeman, J.D. (1994). Mixing Characteristics of Directly Opposed Rows of Jets Injected Normal to a Crossflow in a Rectangular Duct. AIAA-940217 (Also NASA TM 106477).

Liscinsky, D.S., True, B., and Holdeman, J.D. (1993). Experimental Investigation of Crossflow Jet Mixing in a Rectangular Duct. ALAA-932037 (Also NASA TM 106152).

Liscinsky, D.S., True, B., Vranos, A., and Holdeman, J.D. (1992). Experimental Study of Cross-Stream Mixing in a Rectangular Duct. AIAA-92-3090 (Also NASA TM 105694).

Oechsle, V.L. and Holdeman, J.D. (1995). Numerical Mixing Calculations of Confined Reacting Jet Flows in a Cylindrical Duct. AIAA-95-0733 (Also NASA TM 106736).

Oechsle, V.L., Mongia, H.C., and Holdeman, J.D. (1994). Comparison of the Mixing Calculations of the Reacting and Nonreacting Flows in a Cylindrical Duct. AIAA-92-3090 (Also NASA TM 106194).

Oechsle, V.L., Mongia, H.C., and Holdeman, J.D. (1993). An Analytical Study of Dilution Jet Mixing in a Cylindrical Duct. AIAA-932043 (Also NASA TM 106181).

Oechsle, V.L., Mongia, H.C., and Holdeman, J.D. (1992). A Parametric Numerical Study of Mixing in a Cylindrical Duct. AIAA-92-3088 (Also NASA TM 105695).

Smith, C.E., Talpallikar, M.V., and Holdeman, J.D. (1991). A CFD Study of Jet Mixing in Reduced Flow Areas for Lower Combustor Emissions. AIAA-91-2460 (Also NASA TM 104411). 
Sowa. W.A., Kroll, J.T., Samuelsen, G.S., and Holdeman, J.D. (1994). Optimization of Orifice Geometry for Cross-Flow Mixing in a Cylindrical Duct. AIAA-94-0219 (Also NASA TM 106436).

Talpallikar, M.V., Smith, C.E., Lai, M.C. and Holdeman, J.D. (1992). CFD Analysis of Jet Mixing in Low NOx Flametube Combustors. Transactions of the ASME: Journal of Engineering for Gas Turbines and Power, 114, 416-424. (Also ASME-91-GT-217; NASA TM 104466).

Vranos, A., Liscinsky, D.S., True, B., and Holdeman, J.D. (1991). Experimental Study of Cross-Stream Mixing in a Cylindrical Duct. AIAA-91-2459 (Also NASA TM 105180).

Zarzalis, N., Joos, F., Glaeser, B., and Ripplinger, T. (1992). NOx-Reduction by RichLean Combustion. AIAA-92-3339. 

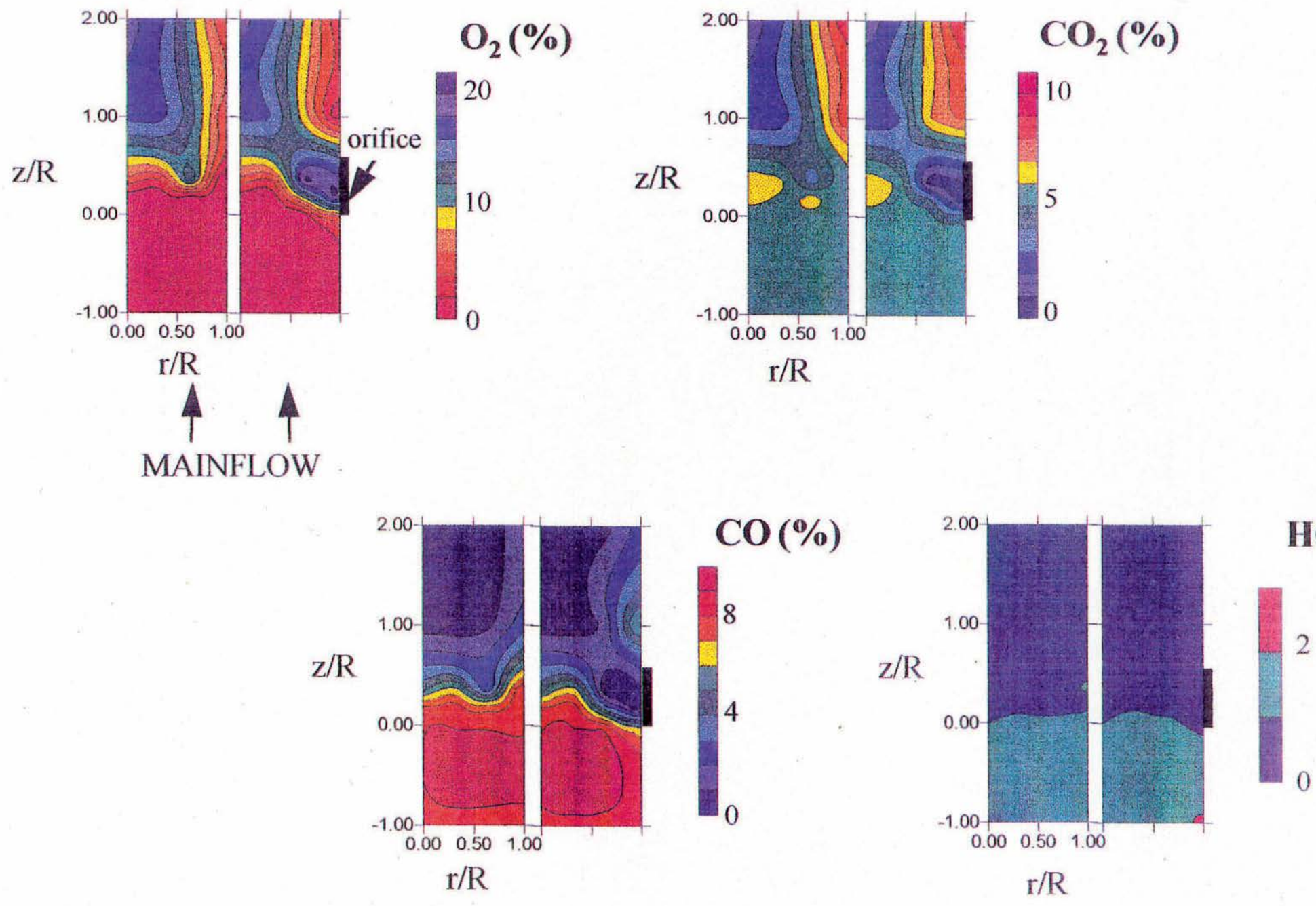

$\mathrm{HC}(\%)$

Figure 5a. Averaged Axial History of Species Concentrations for the 8-Hole Module (for each pair, left plot is midplane, right plot is centerplane) 
Page intentionally left blank 


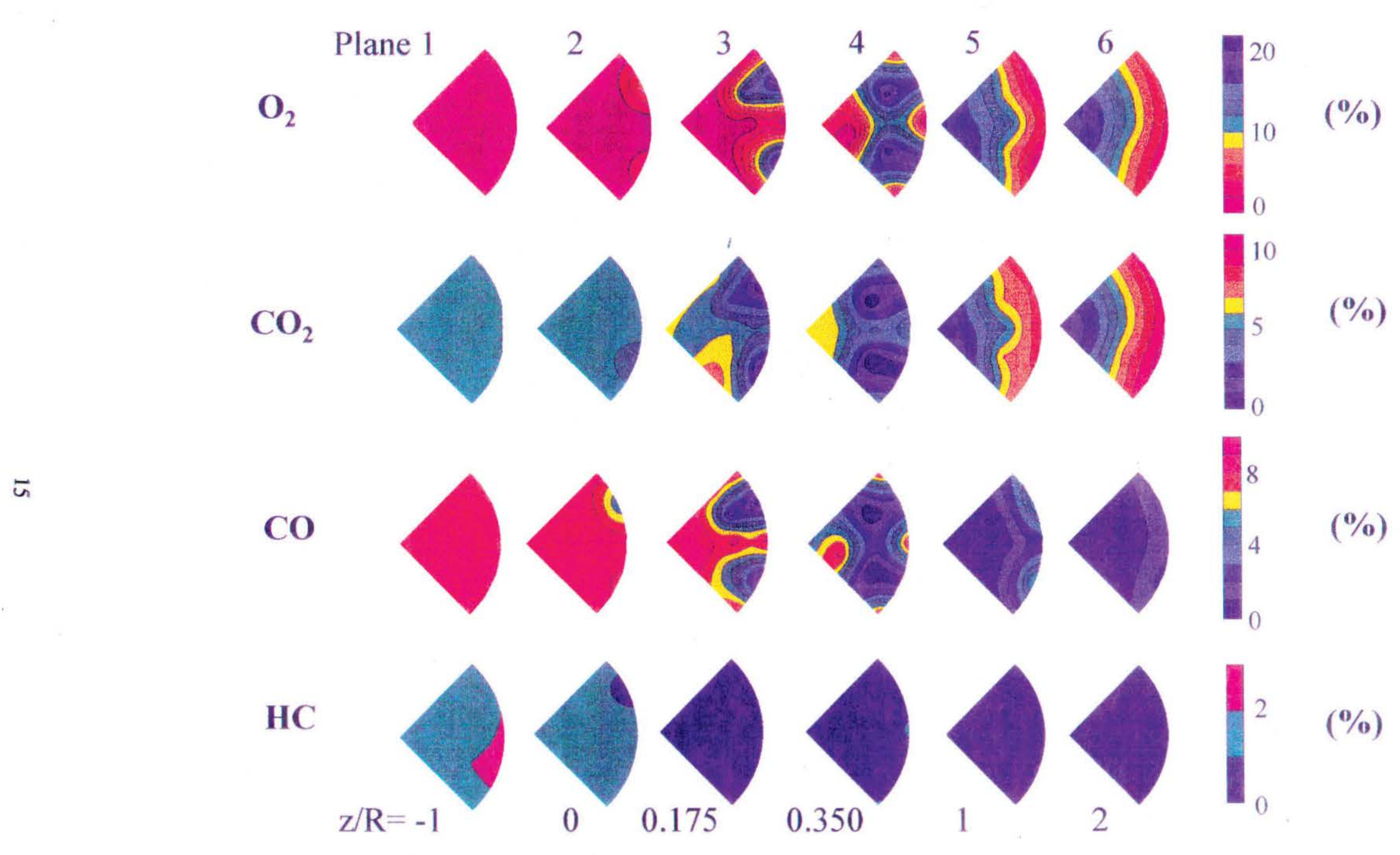

Figure 5b. Sector Profiles of Species for the 8-Hole Module 
Page intentionally left blank 
8 HOLES

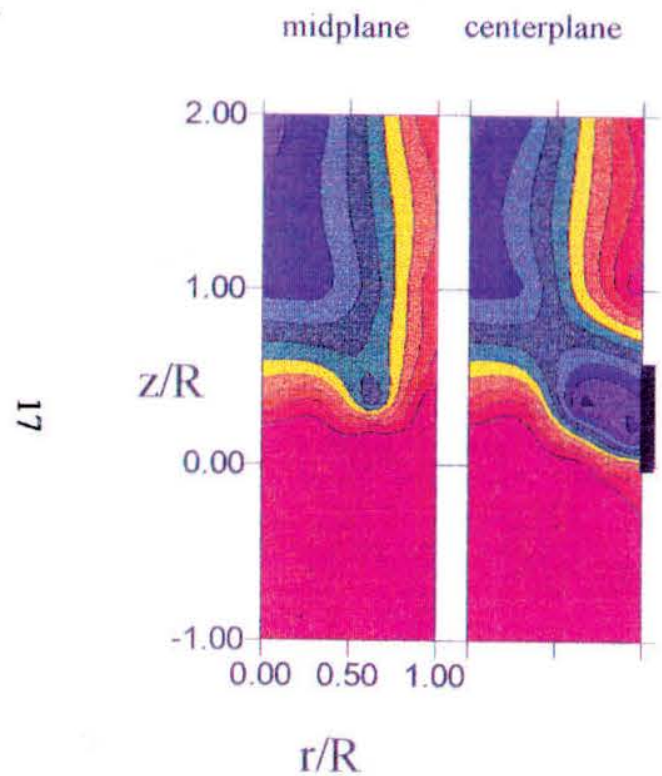

10 HOLES

midplane centerplane
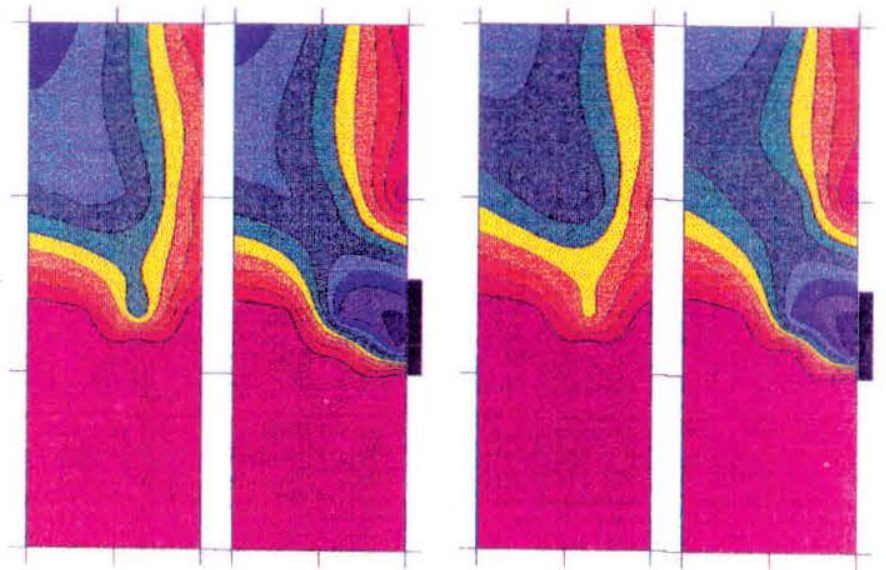

4

4

MAINFLOW
12 HOLES

midplane centerplane

$(\%)$

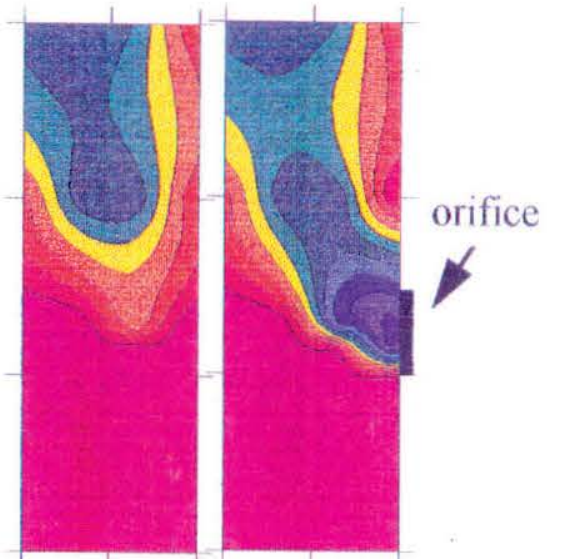

20.00

18.00

16.00

14.00

12.00

10.00

8.00

6.00

4.00

2.00

0.00

Figure 6. Averaged Axial History of $\mathrm{O}_{2}$ Evolution at Two Radial-Axial Cross Sections 
Page intentionally left blank 


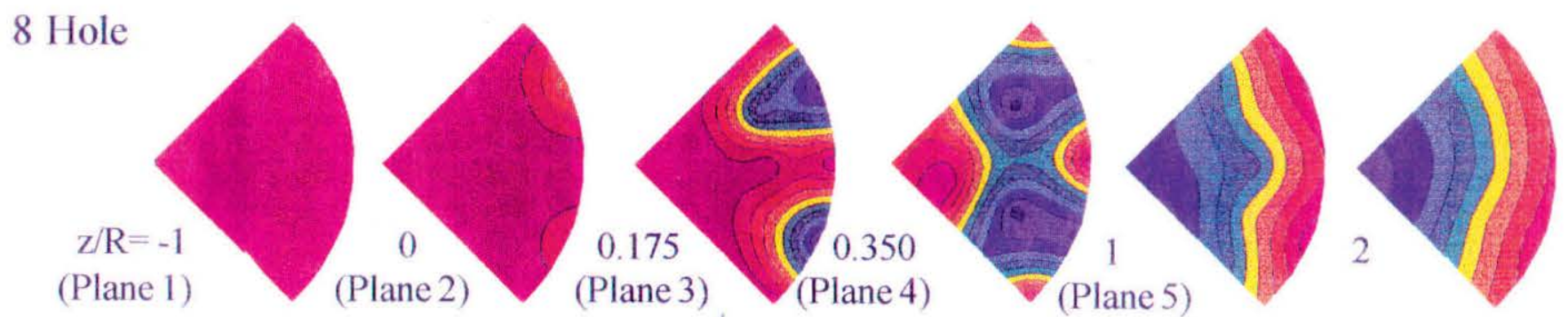

9 Hole
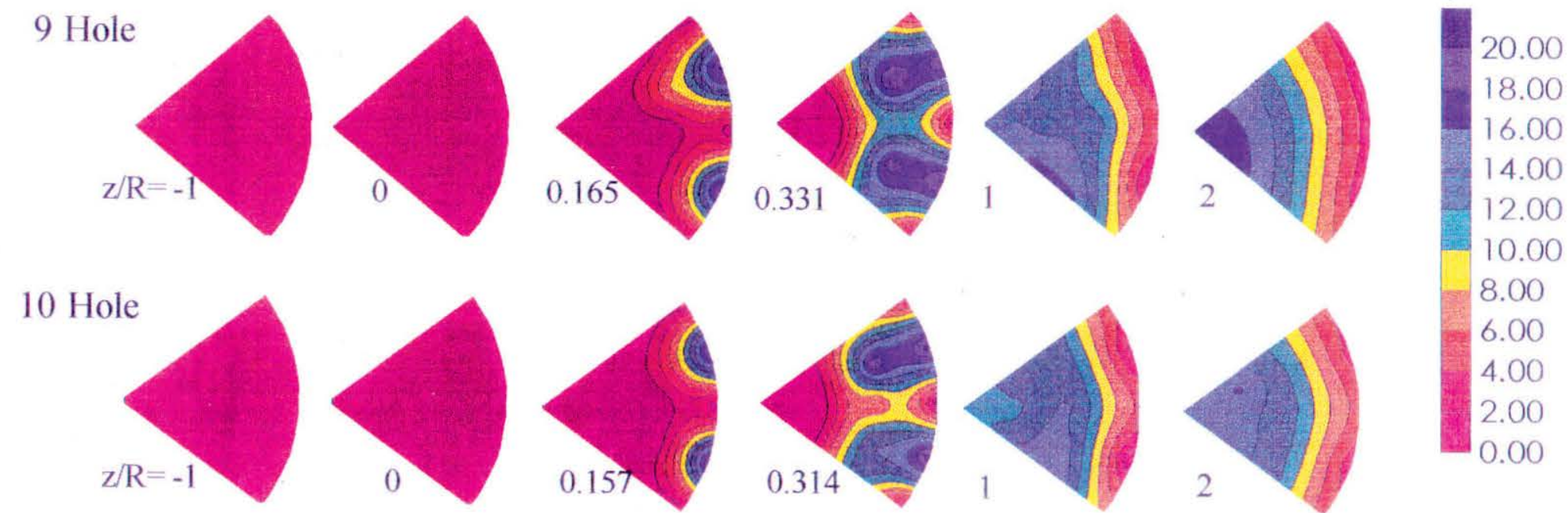

8.00

6.00

4.00

2.00

0.00

12 Hole
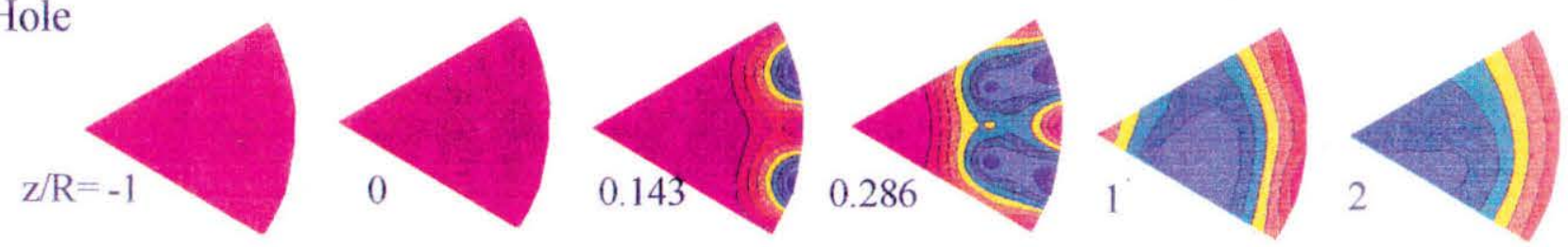

Figure 7. $\mathrm{O}_{2}$ Sector Profiles for the 8-, 9-, 10-, and 12-Hole Modules 
Page intentionally left blank 
8 HOLES

midplane centerplane

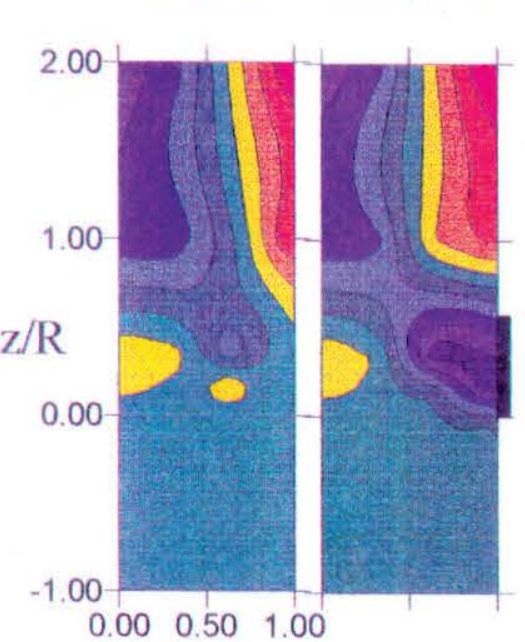

$\mathrm{r} / \mathrm{R}$
10 HOLES

midplane centerplane
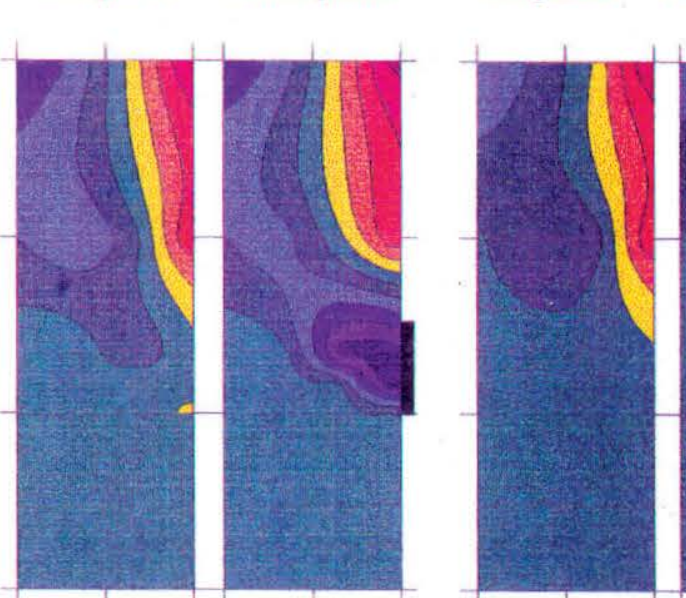

4

midplane centerplane

$(\%)$
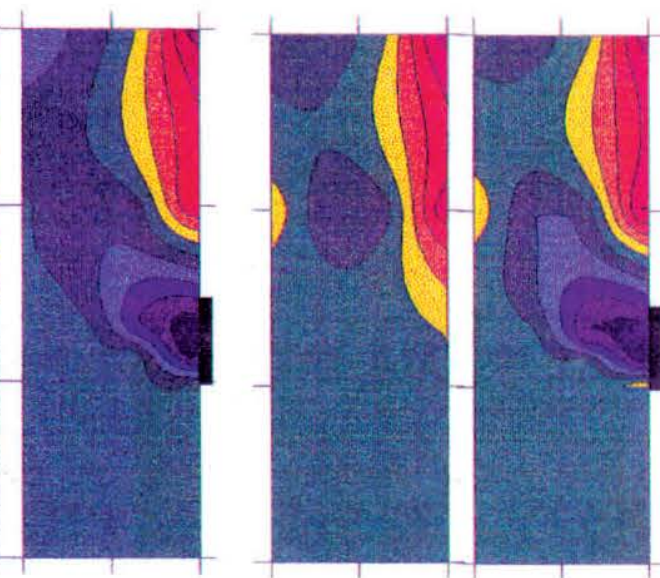

10.00

9.00

8.00

7.00

6.00

5.00

4.00

3.00

2.00

1.00

0.00 
Page intentionally left blank 
8 Hole

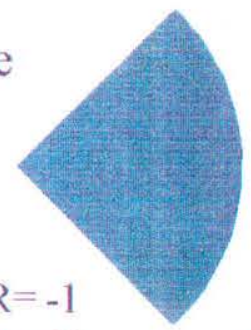

(Plane 1)

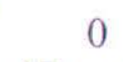

(Plane 2)

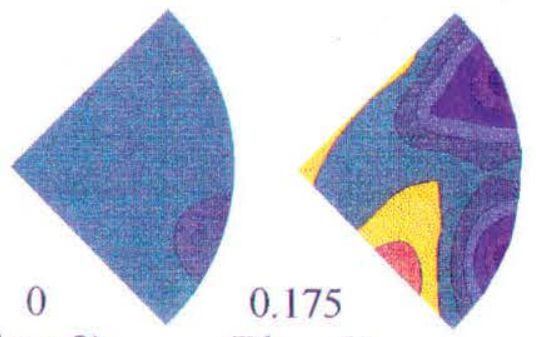

(Plane 3)

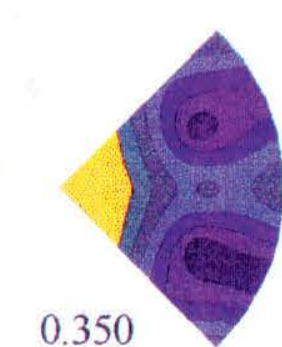

(Plane 4)

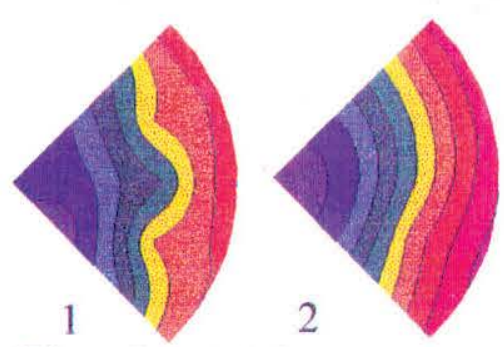

(Plane 5) (Plane 6)
9 Hole
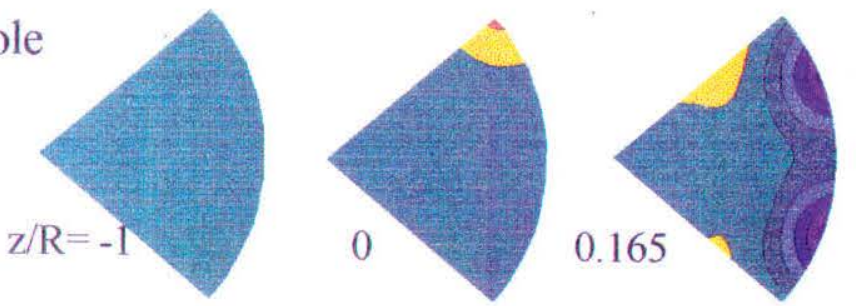

$\tilde{\omega}$

10 Hole
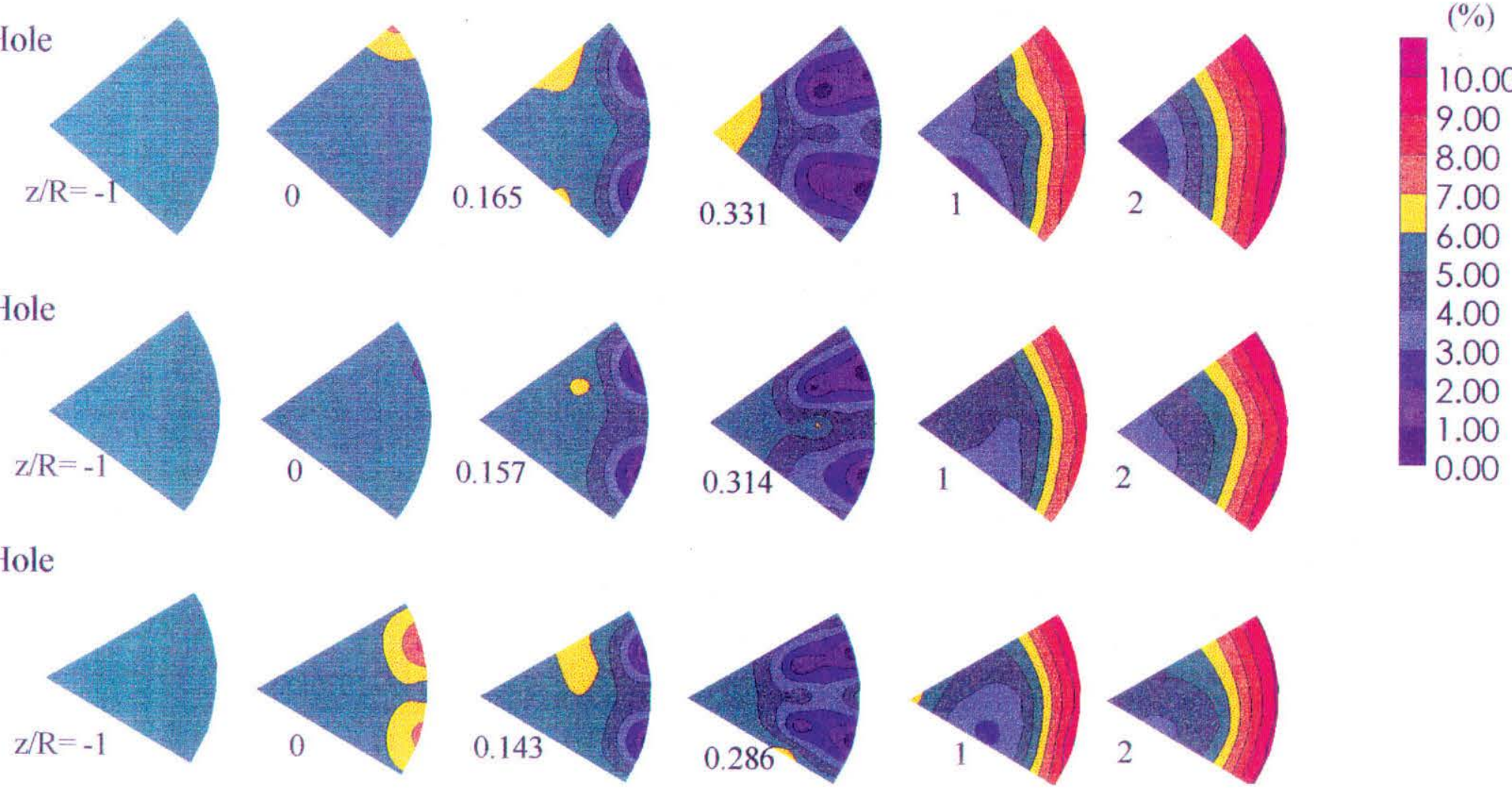

Figure 9. $\mathrm{CO}_{2}$ Sector Profiles for the 8-, 9-, 10- and 12-Hole Modules 
Page intentionally left blank 
8 HOLES

midplane centerplane

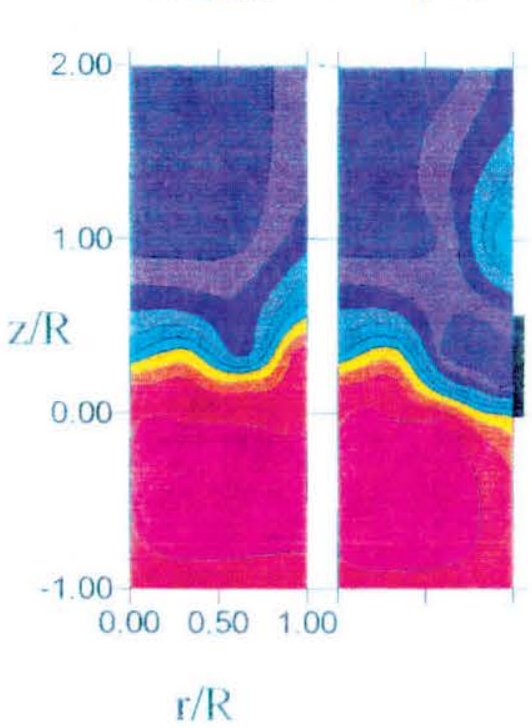

$r / R$
9 HOLES

midplane

centerplane
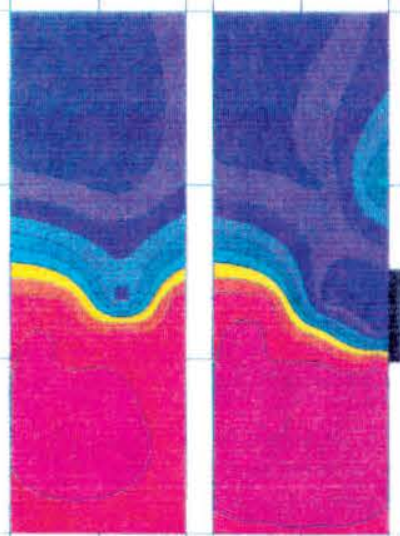

10 HOLES

midplane

centerplane
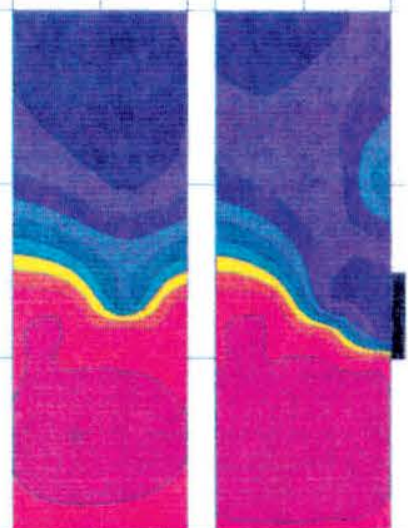

4

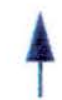

MAINFLOW

\section{HOLES}

midplane centerplane

$(\%)$

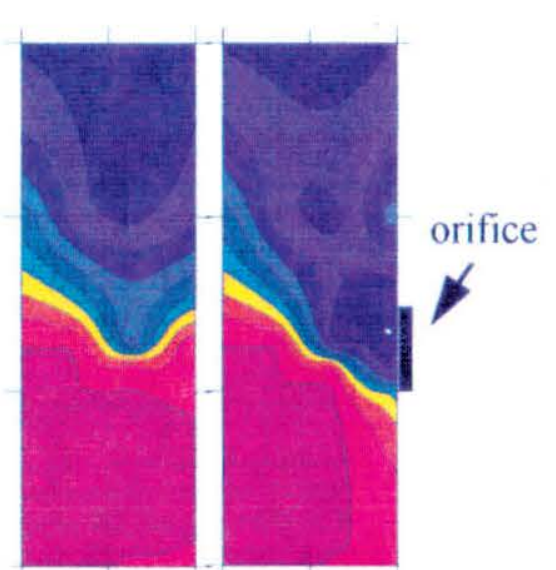

9.00

8.00

7.00

6.00

5.00

4.00

3.00

2.00

1.00

0.00 
Page intentionally left blank 
8 Hole

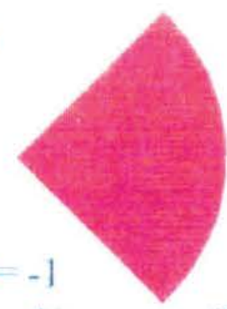

(Plane 1)

(Plane 2)
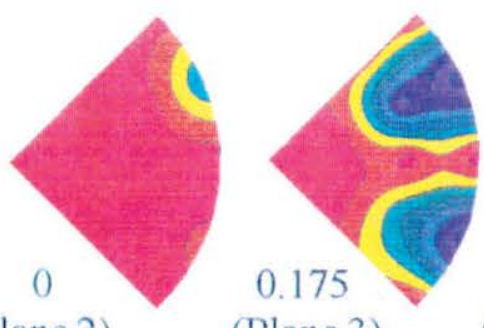

(Plane 3)
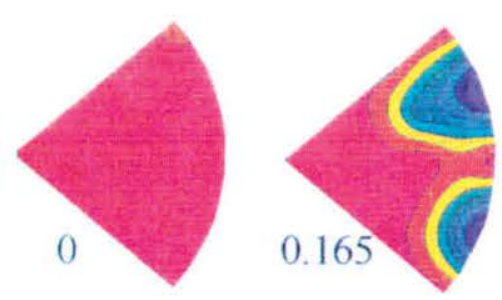

(Plane 4)

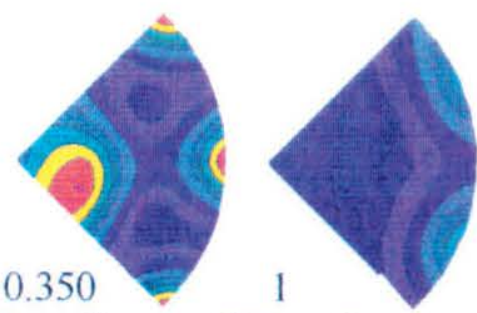

(Plane 5)
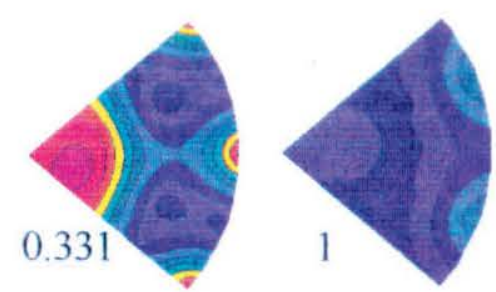

(Plane 6)

9 Hole<smiles>[R]C1CCCC1</smiles>

N
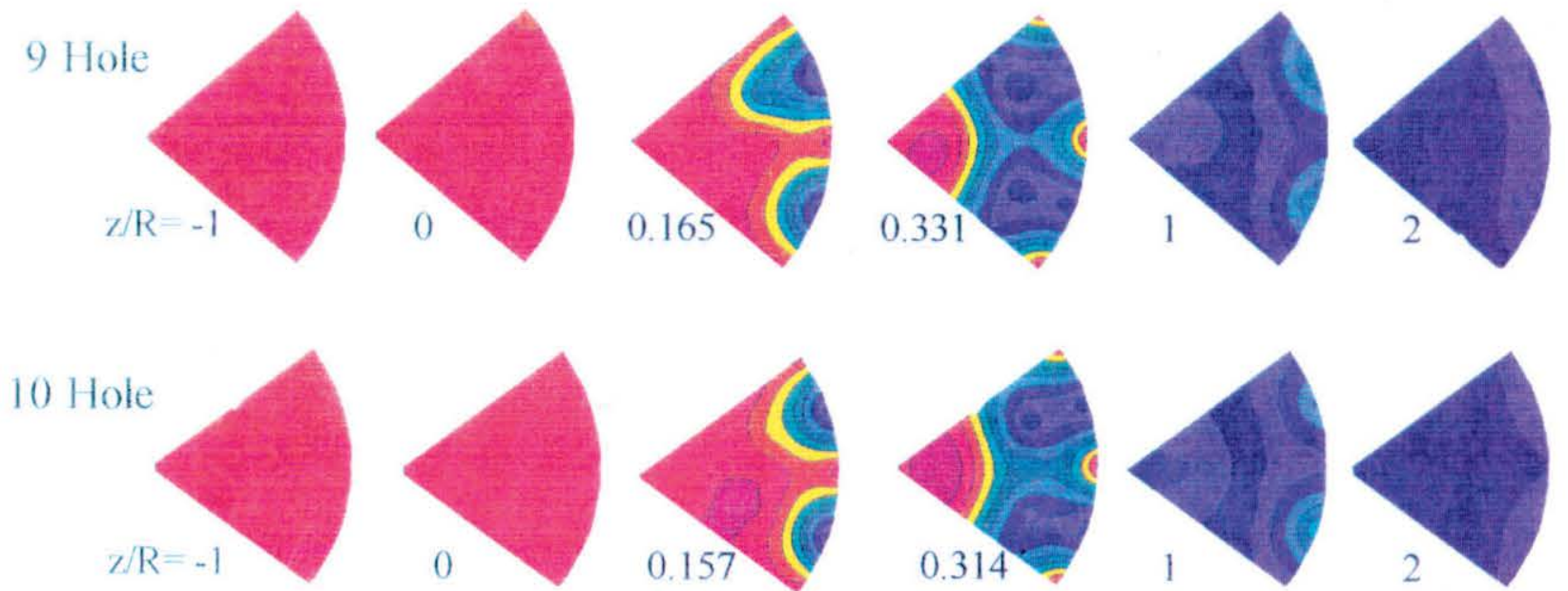

9.00

8.00

$-7.00$

$-6.00$

5.00

4.00

3.00

2.00

1.00

0.00
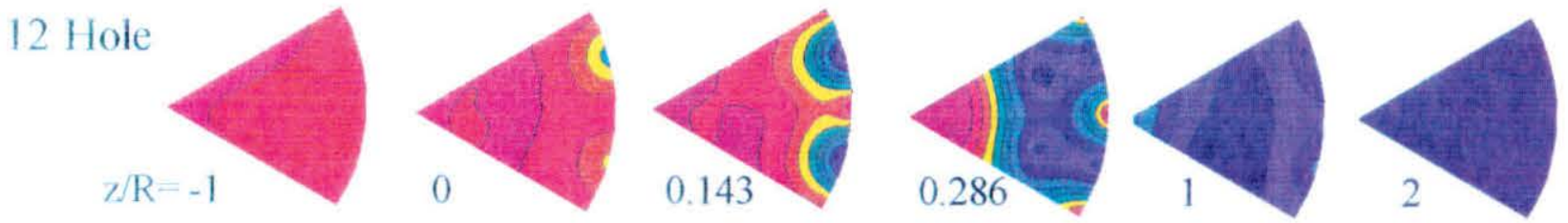

Figure 11. CO Sector Profiles for the 8-, 9-, 10-, and 12-Hole Modules 
Page intentionally left blank 
8 HOLES

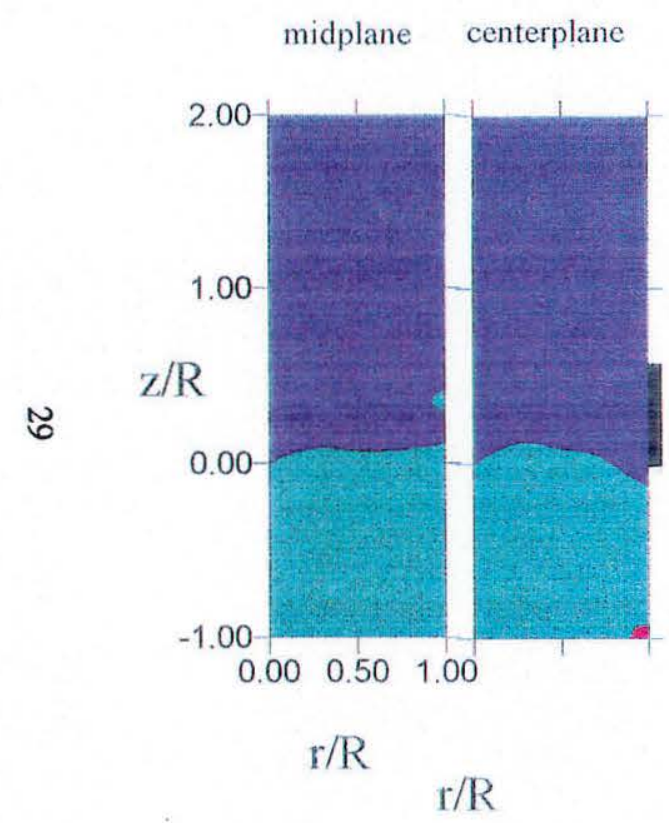

9 HOLES

midplane centerplane

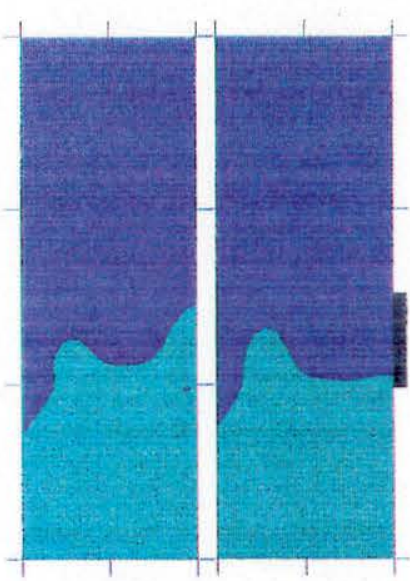

.
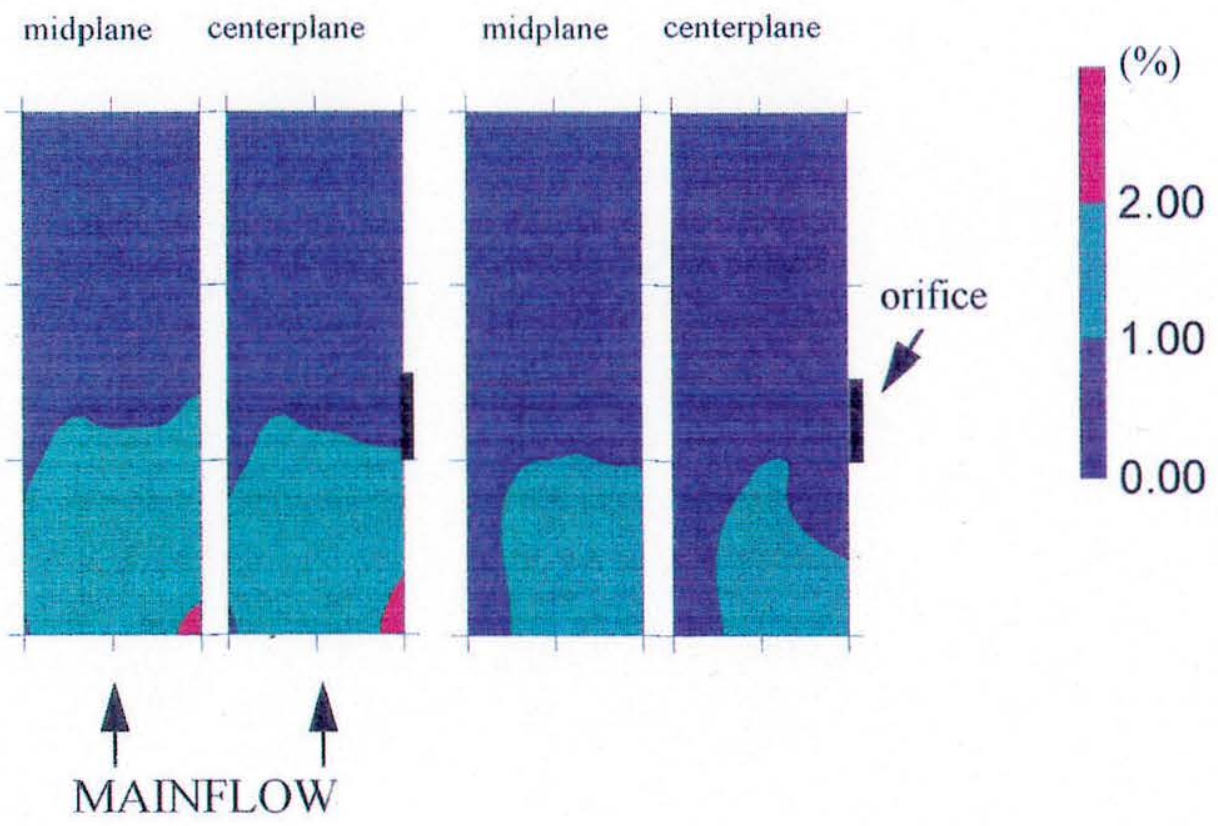

\section{HOLES}


Page intentionally left blank 

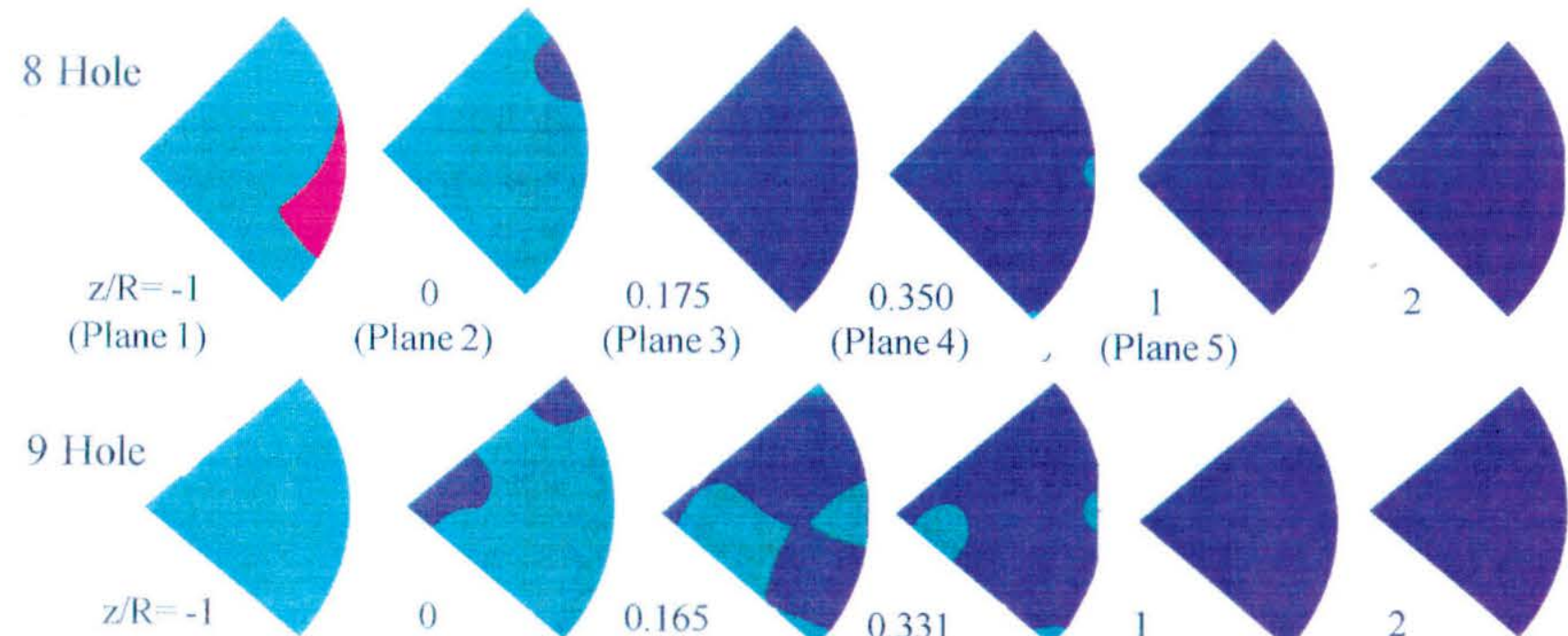

(Plane 2)

(Plane 3)

(Plane 4)

(Plane 5)
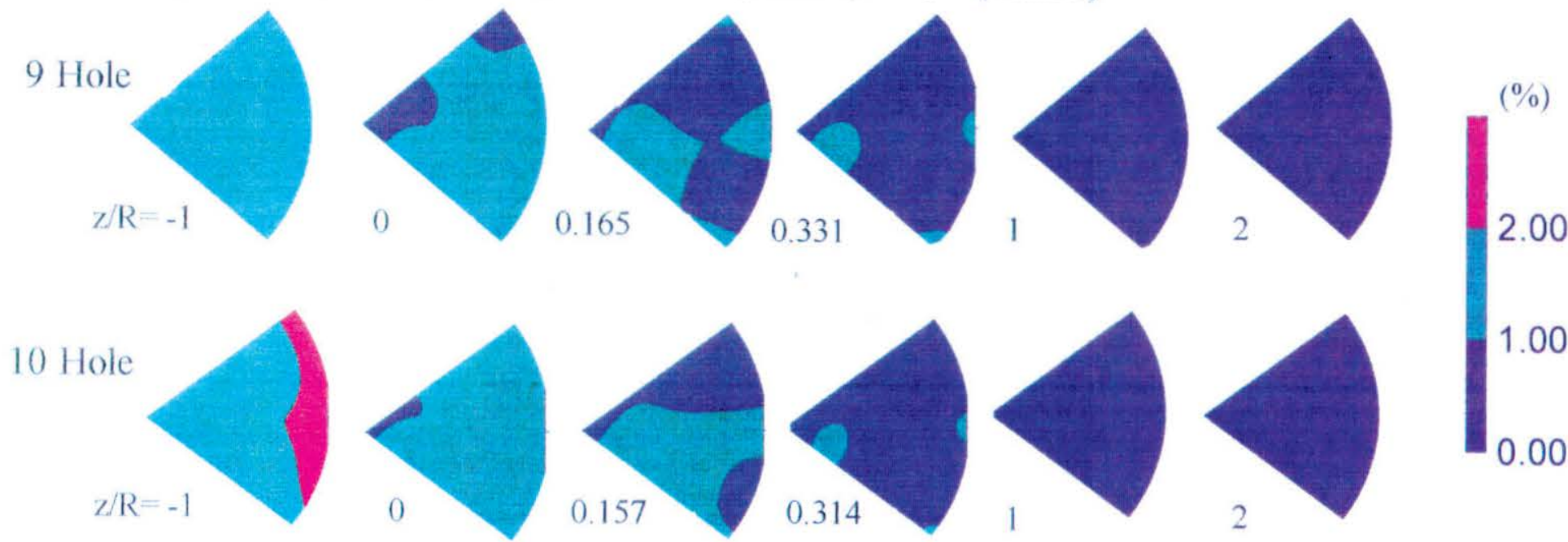

1.00

12 Hole
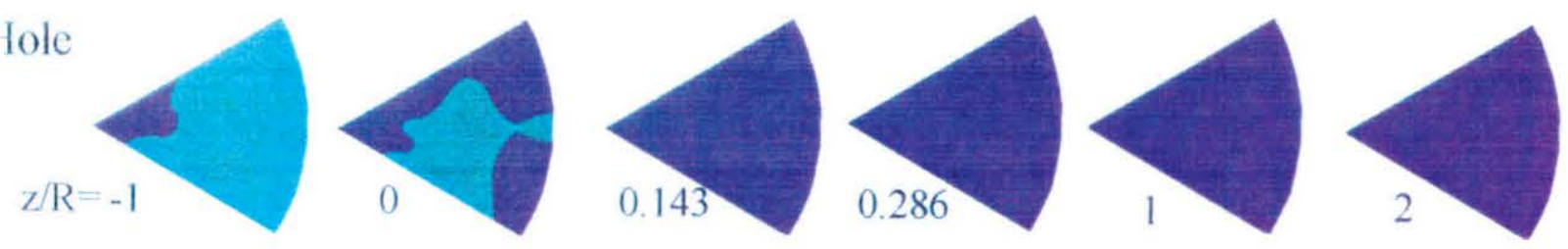

Figure 13. HC Sector Profiles for the 8-, 9-, 10-, and 12-Hole Modules 
Public reporting burden for this collection of information is estimated to average 1 hour per response, including the time for reviewing instructions, searching existing data sources, gathering and maintaining the data needed, and completing and reviewing the collection of information. Send comments regarding this burden estimate or any other aspect of this collection of information, including suggestions for reducing this burden, to Washington Headquarters Services, Directorate for Information Operations and Reports, 1215 Jefferson Davis Highway, Suite 1204, Arlington, VA 22202-4302, and to the Office of Management and Budget, Paperwork Reduction Project (0704-0188), Washington, DC 20503.

\begin{tabular}{|l|l|l}
\hline 1. AGENCY USE ONLY (Leave blank) & $\begin{array}{c}\text { 2. REPORT DATE } \\
\text { July } 1995\end{array}$ & $\begin{array}{r}\text { 3. REPORT TYPE AND DATES COVERED } \\
\text { Technical Memorandum }\end{array}$ \\
\hline
\end{tabular}

\section{TITLE AND SUBTITLE}

Jet Mixing in a Reacting Cylindrical Crossflow

\section{AUTHOR(S)}

M.Y. Leong, G.S. Samuelsen, and J.D. Holdeman

\section{FUNDING NUMBERS}

WU-537-02-20-00

8. PERFORMING ORGANIZATION REPORT NUMBER

E-9736

National Aeronautics and Space Administration

Lewis Research Center

Cleveland, Ohio 44135-3191

10. SPONSORING/MONITORING AGENCY REPORT NUMBER

National Aeronautics and Space Administration

Washington, DC 20546-0001

NASA TM-106975

AIAA-95-3109

\section{SUPPLEMENTARY NOTES}

Prepared for the 31st Joint Propulsion Conference and Exhibit cosponsored by AIAA, ASME, SAE, and ASEE, San Diego, California, July 10-12, 1995. M.Y. Leong and G.S. Samuelsen, UCI Combustion Laboratory, University of California, Irvine, California 92717; J.D. Holdeman, NASA Lewis Research Center. Responsible person, J.D. Holdeman, organization code 2650, (216) 433-5846.

12a. DISTRIBUTION/AVAILABILITY STATEMENT 12b. DISTRIBUTION CODE

Unclassified - Unlimited

Subject Category: 07

Available electronically at http://gltrs.grc.nasa.gov/GLTRS

This publication is available from the NASA Center for AeroSpace Information, (301) 621-0390.

13. ABSTRACT (Maximum 200 words)

This paper addresses the mixing of air jets into the hot, fuel-rich products of a gas turbine primary zone. The mixing, as a result, occurs in a reacting environment with chemical conversion and substantial heat release. The geometry is a crossflow confined in a cylindrical duct with side-wall injection of jets issuing from round orifices. A specially designed reactor, operating on propane, presents a uniform mixture without swirl to mixing modules consisting of 8, 9, 10, and 12 holes at a momentum-flux ratio of 57 and a jet-to-mainstream mass-flow ratio of 2.5. Concentrations of $\mathrm{O}_{2}, \mathrm{CO}_{2}, \mathrm{CO}$, and $\mathrm{HC}$ are obtained upstream, downstream, and within the orifice plane. $\mathrm{O}_{2}$ profiles indicate jet penetration white $\mathrm{CO}_{2}, \mathrm{CO}$, and $\mathrm{HC}$ profiles depict the extent of reaction. Jet penetration is observed to be a function of the number of orifices and is found to affect the mixing in the reacting system. The results demonstrate that one module (the 12-hole) produces nearoptimal penetration defined here as jet penetration closest to the module half-radius, and hence the best uniform mixture at a plane one duct radius from the orifice leading edge.

\section{SUBJECT TERMS}

Dilution; Jet mixing flow; Gas turbines; Emissions; Combustion chamber 15. NUMBER OF PAGES

\begin{tabular}{|c|c|c|}
\hline $\begin{array}{c}\text { 17. SECURITY CLASSIFICATION } \\
\text { OF REPORT } \\
\text { Unclassified }\end{array}$ & $\begin{array}{c}\text { 18. SECURITY CLASSIFICATION } \\
\text { OF THIS PAGE } \\
\text { Unclassified }\end{array}$ & $\begin{array}{c}\text { 19. SECURITY CLASSIFICATION } \\
\text { OF ABSTRACT } \\
\text { Unclassified }\end{array}$ \\
\hline
\end{tabular}

